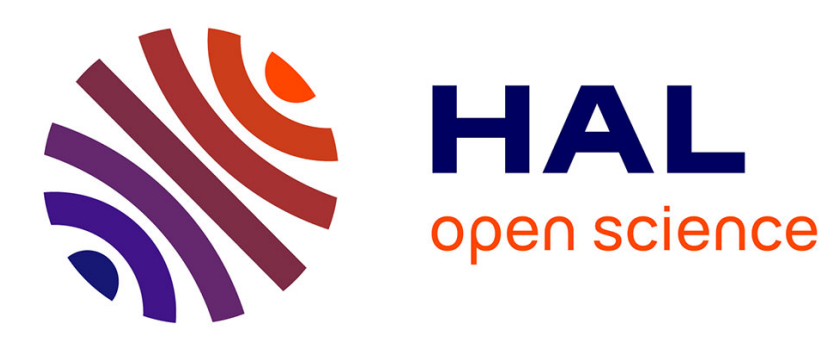

\title{
Motion planning control of the airpath of a S.I. engine with Valve Timing Actuators
}

Thomas Leroy, Jonathan Chauvin, Nicolas Petit, Gilles Corde

\section{To cite this version:}

Thomas Leroy, Jonathan Chauvin, Nicolas Petit, Gilles Corde. Motion planning control of the airpath of a S.I. engine with Valve Timing Actuators. Fifth IFAC Symposium on Advances in Automotive Control, Aug 2007, Seascape Resort, United States. pp.1-7, 10.3182/20070820-3-US-2918.00083 . hal-00563394

\section{HAL Id: hal-00563394 \\ https: / hal-mines-paristech.archives-ouvertes.fr/hal-00563394}

Submitted on 4 Feb 2011

HAL is a multi-disciplinary open access archive for the deposit and dissemination of scientific research documents, whether they are published or not. The documents may come from teaching and research institutions in France or abroad, or from public or private research centers.
L'archive ouverte pluridisciplinaire HAL, est destinée au dépôt et à la diffusion de documents scientifiques de niveau recherche, publiés ou non, émanant des établissements d'enseignement et de recherche français ou étrangers, des laboratoires publics ou privés. 


\title{
MOTION PLANNING CONTROL OF THE AIRPATH OF AN S.I. ENGINE WITH VALVE TIMING ACTUATORS
}

\author{
T. Leroy ${ }^{* * *}$ J. Chauvin ${ }^{*}$ N. Petit ${ }^{* *}$ G. Corde ${ }^{*}$ \\ * Institut Français du Pétrole, 1 et 4 Avenue de Bois \\ Préau, 92852 Rueil Malmaison, France \\ ** Centre Automatique et Systèmes, École des Mines de \\ Paris, \\ 60, bd St Michel, 75272 Paris, France
}

\begin{abstract}
We address the control of the airpath of a turbocharged S.I. engine equipped with Variable Valve Timing actuators (VVT). Compared to standard configurations, the engine does not possess any external EGR (Exhaust Gas Recirculation) loop. Rather, VVT are used to produce internal EGR, providing similar beneficial effects in terms of emissions reduction. The airpath dynamics takes the form of a single mono-dimensional air balance in the intake manifold. In this equation, the VVT act as a disturbance by impacting on the air mass flow through the inlet valves. This impact can be estimated from real-time measurements. We use this information in a motion planning based control strategy by, successively, turning the driver's torque demand into a trajectory generation problem for the air mass contained in the intake manifold, and then deriving an intake manifold pressure trajectory. Supportive simulation results show the relevance of this approach and suggest ways of further improvements.
\end{abstract}

Keywords: Airpath control, SI Engine, VVT, Motion planning

\section{INTRODUCTION}

Lately, downsizing (reduction of the engine size) has appeared as a major way of reducing fuel consumption of SI engines. Downsizing lowers pumping losses under partial load and, thus, saves energy (see (Lecointe and Monnier, 2003)). To compensate the induced power losses, turbochargers are used. For such engines, Variable Valve Timing (VVT) devices are used to improve combustion efficiency and reduce $\mathrm{NO}_{x}$ emissions.

In this paper, we focus on two control objectives. What the driver primarily expects from the engine control system is to respond to its torque demand. Since SI engine dynamics are mostly represented by the airpath, controlling the torque is equivalent to controlling the air mass aspirated in the cylinder. Besides, it is also desired to reduce engine pollutant emissions. Three-way catalysts (TWC) are used to reduce $\mathrm{CO}, \mathrm{HC}$ and $\mathrm{NO}_{x}$ created by the combustion. However, to efficiently convert these species to water and carbon dioxide, TWC need that the air/fuel ratio resides in a very narrow region around the stoichiometric value 1 (see Figure 1) ${ }^{1}$. In practice, the air mass in the cylinder, which is not measured, can be estimated to adjust the injected fuel quantity so that the air/fuel ratio equals the stoichiometric ideal value.

\footnotetext{
1 The air/fuel ratio under consideration here is the ratio of trapped air mass and fuel mass in the cylinder when the valves are closed, it is defined by $\lambda \triangleq \frac{1}{14.6} \frac{M_{\text {air }}}{M_{\text {fuel }}}$.
} 


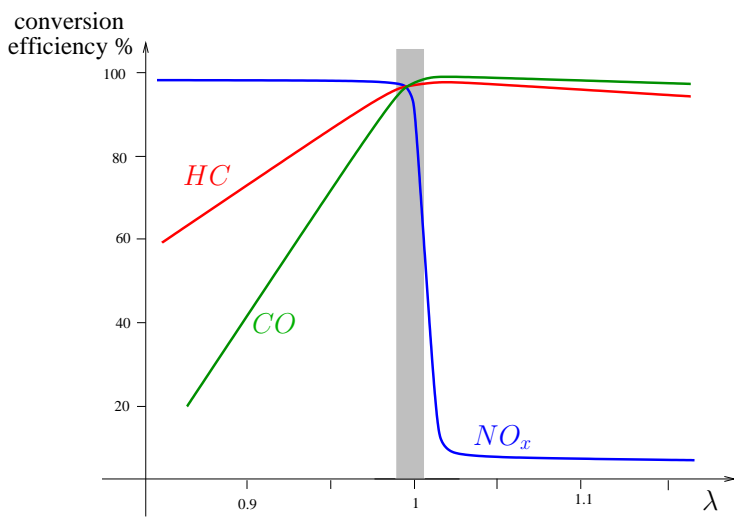

Fig. 1. Three-way catalytic converter (TWC) efficiency as a function of air/fuel ratio.

On classic SI engines, a variable named the "volumetric efficiency" is used to estimate the air mass in the cylinder through balance equations. Usually, its values are calibrated under steady state running engine conditions and ambient temperature and pressure conditions (see (Chevalier et al., 2000b), (Andersson, 2005), (Chevalier et al., 2000a), (Eriksson et al., 2002) for example). The volumetric efficiency is modelled as a nonlinear function of the engine speed, which is usually easily available from measurements, and the intake pressure.

This calibration task is much more involved in the case of our downsized engines. Indeed, the position of the VVT actuator affects the exhaust manifold pressure and the residual gas mass trapped inside the cylinder. This has an influence on the volumetric efficiency which, as has been discussed, is the core variable when computing the fuel injection feedforward term. Figure 2 reports experiments stressing the strong influence of VVT on the volumetric efficiency.

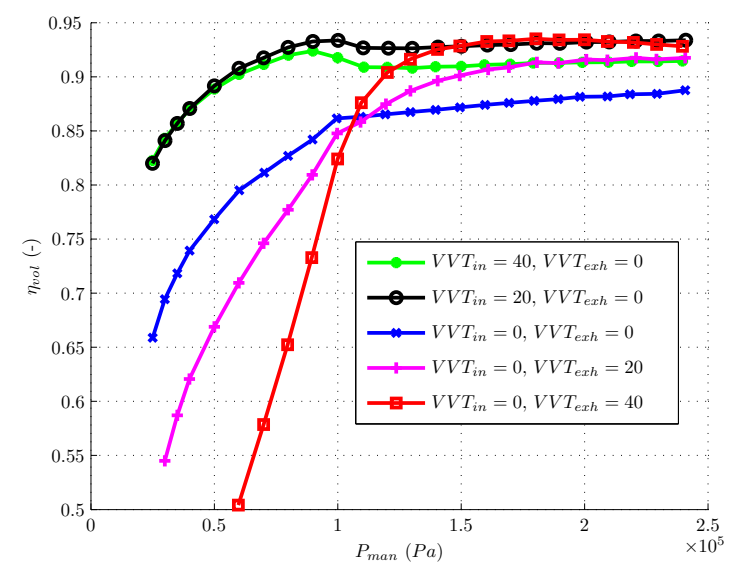

Fig. 2. Experimental volumetric efficiency, for different VVT positions, as a function of the intake manifold pressure at constant engine speed (2000 rpm).

Experimentally, it is difficult to obtain reliable look-up tables of the volumetric efficiency for every engine speed, intake pressure and VVT po- sition. Yet, observers can be used to solve an input estimation problem (see (Stotsky and Kolmanovsky, 2002) for a global overview) and to estimate the trapped air mass in the cylinder. Volumetric efficiency modelling and determination by the measurement of the intake manifold air flow, the manifold air pressure and temperature has been adressed previously in the literature (see (Andersson and Eriksson, 2001), (Chevalier et al., 2000a), (Chauvin et al., 2006b), (Grizzle et al., 1994)). These approaches lead to an observer (usually an extended Kalman filter) relying on a mean-value model of the intake flow (at the TDC time-scale). This estimation of the trapped air mass is not suffisant to get the expected amount of fuel. Actually, because of computational and injection duration, fuel control signal is only applied about 2 TDC later (see (Chevalier et al., 2000a)). To compensate the delay, port air mass flow must be predicted. The prediction is then given as a feedforward to compute a fuel mass set point $\left(M_{\text {fuel }}^{F F}=\frac{1}{14.6} M_{\text {air }}^{\text {pred }}\right)$. This strategy is the most used for air/fuel ratio control in SI engine without VVT devices. This is more difficult in VVT SI engines. Indeed, there is no uniqueness of the relationship between intake pressure and air mass trapped (see Figure 2), so a simple prediction of the intake pressure from a prediction of the throttle position is no more possible. That is why we propose an alternative approach. We simply use a planned trajectory of the air mass as a feedforward term in the fuel injection $\left(M_{\text {fuel }}^{F F}=\frac{1}{14.6} M_{a i r}^{m p}\right)$. A simple nonlinear observer reconstructs the volumetric efficiency. It is only used to convert the air mass control problem into an intake pressure control objective. Convergence of the observer guarantees that, asymptotically, the air mass set point is reached. The main advantage of substituting the estimated value of the air mass with a (varying) set point is that it allows an easy synchronization of the air and fuel controllers. We send the future reference signal (two TDC ahead, see Figure 4) to the fuel injection system and the current reference to the air path controller. This synchronization improves the matching of the air mass and the fuel mass, yielding a better tracking of the air/fuel ratio reference. This strategy appears efficient as is demonstrated by simulation results.

The paper is organised as follows. In Section 2, we present the reference model of the intake manifold. We consider a mass balance equation and a model of the aspirated flow. In Section 3, we present our control structure. In Section 4, we propose an observer that estimates a correcting term in the volumetric efficiency appearing in the aspirated flow. It allows to take into account variables that are not considered in the data fit (VVT, exhaust pressure, exhaust temperature, ...). In Section 5, we detail the motion planning technique 
and the feedforward control strategy. Section 6 briefly reports the model used for simulation and presents obtained results. We finally conclude and give future directions in Section 7.

\section{AIR PATH MODELLING}

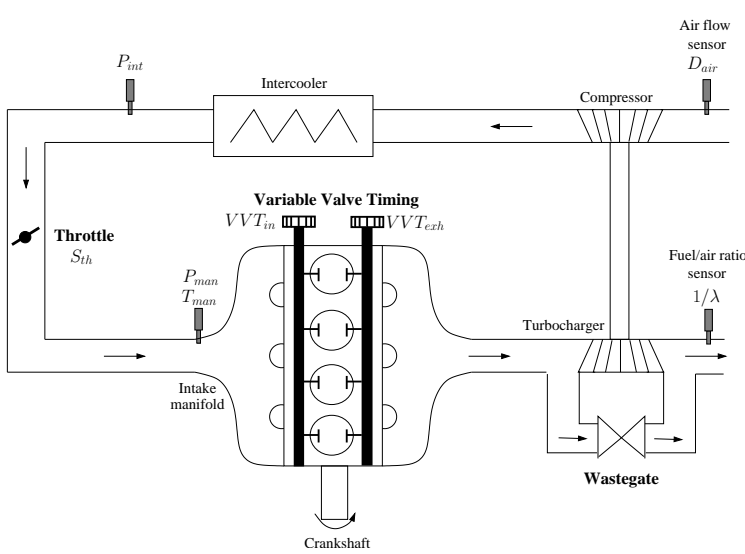

Fig. 3. Engine scheme, VVT are used to produce internal EGR.

\subsection{Mass balance in the intake manifold}

Notations are given in Table 1 . We consider the intake manifold as a fixed volume for which the thermodynamic states (pressures, temperatures, composition) are assumed homogeneous. We neglect variations of temperature in the volume (as in (Guzzella and Onder, 2004), (Andersson and Eriksson, 2001) for example), i.e. $\dot{T}_{m a n}=0$. The mass balance in the intake manifold gives

$$
\dot{P}_{\text {man }}=\frac{R T_{\text {man }}}{V_{\text {man }}}\left(D_{a i r}-D_{a s p}\right)
$$

where $P_{\text {man }}$ and $T_{\text {man }}$ are measured by sensors located in the intake manifold, and $D_{\text {air }}$ can be obtained by an air flow sensor in the intake of the engine as represented in Figure 3. $D_{a s p}$ is the air flow aspirated into the cylinders. Subsequently we model the air mass flow through inlet valves (Heywood, 1988),

$$
D_{a s p}=\eta_{v o l}\left(P_{m a n}, \Phi\right) \frac{V_{c y l}}{R T_{\text {man }}} \frac{N_{e}}{30} P_{\text {man }}
$$

where $\eta_{\text {vol }}\left(P_{\text {man }}, \Phi\right)$ is the volumetric efficiency. It depends on the intake manifold pressure, $P_{\text {man }}$, and on other parameters such as the engine speed, $N_{e}$, and the VVT positions, i.e. $\Phi \triangleq$ $\left(N_{e}, V V T_{i n}, V V T_{e x h}\right)$.

\subsection{Reference model}

Let $x \triangleq P_{\text {man }}$ and $y \triangleq P_{\text {man }}$ be the state and the measurement of the system, respectively. We note $\alpha_{i n t} \triangleq \frac{R T_{\operatorname{man}}}{V_{\operatorname{man}}}$ and $\beta_{\text {int }} \triangleq \frac{V_{\text {cyl }}}{R T_{\operatorname{man}}} \frac{N_{e}}{30}$. The control is

\begin{tabular}{|c|c|c|}
\hline Symbol & Description & Unit \\
\hline$D_{\text {air }}$ & Manifold air flow & $k g . s^{-1}$ \\
\hline$D_{a s p}$ & $\begin{array}{l}\text { Aspirated air flow into the } \\
\text { cylinders }\end{array}$ & $k g . s^{-1}$ \\
\hline$M_{a i r}$ & $\begin{array}{l}\text { Trapped air mass into the } \\
\text { cylinders }\end{array}$ & $k g$ \\
\hline$N_{e}$ & Engine speed & rpm \\
\hline$P_{\text {int }}$ & Intercooler pressure & $\mathrm{Pa}$ \\
\hline$P_{\text {man }}$ & $\begin{array}{l}\text { Pressure in the intake mani- } \\
\text { fold }\end{array}$ & $\mathrm{Pa}$ \\
\hline$R$ & Ideal gas constant & $J \cdot k g^{-1} \cdot K^{-1}$ \\
\hline$S_{t h}$ & Openning throttle section & $m^{2}$ \\
\hline$T_{\text {man }}$ & $\begin{array}{l}\text { Temperature in the intake } \\
\text { manifold }\end{array}$ & $K$ \\
\hline$V_{\text {cyl }}$ & Cylinder volume & $m^{3}$ \\
\hline$V_{\text {man }}$ & Intake manifold volume & $m^{3}$ \\
\hline$V V T_{i n}$ & Intake VVT position & ${ }^{\circ} \mathrm{CA}$ \\
\hline$V V T_{e x h}$ & Exhaust VVT position & ${ }^{\circ} \mathrm{CA}$ \\
\hline$\eta_{v o l}$ & Volumetric efficiency & - \\
\hline$\lambda$ & Air/fuel ratio & - \\
\hline$\Phi$ & $\Phi=\left(N_{e}, V V T_{i n}, V V T_{e x h}\right)$ & - \\
\hline
\end{tabular}

Table 1. Nomenclature

the throttle opening section $u \triangleq S_{t h}$. The mass air flow through the throttle now writes $D_{\text {air }} \triangleq u f(x)$ where $f(x)$ is the mass flow rate (Heywood, 1988)

$$
\begin{aligned}
& f(x)= \\
& \kappa P_{\text {int }}\left\{\begin{array}{l}
\left(\frac{x}{P_{\text {int }}}\right)^{\frac{1}{\gamma}} \sqrt{\frac{2 \gamma}{\gamma-1}\left(1-\left(\frac{x}{P_{\text {int }}}\right)^{\frac{\gamma-1}{\gamma}}\right)} \\
\sqrt{\gamma\left(\frac{2}{\gamma+1}\right)^{\frac{\gamma+1}{\gamma-1}}} \quad \text { if } \frac{x}{P_{\text {int }}}>0.528 \\
\text { else }
\end{array}\right.
\end{aligned}
$$

where $\kappa=\frac{1}{\sqrt{R T_{\operatorname{man}}}}, P_{\text {int }}$ is the upstream pressure of the throttle, and $\gamma$ is the specific heats ratio in the intake manifold.

The air mass trapped in the cylinder is given by $z \triangleq M_{\text {air }}$. A simple integration gives $z=$ $D_{\text {asp }} \frac{30}{N_{e}}$. With the notations reported in Table 2, the reference system is

$$
\left\{\begin{aligned}
\dot{x} & =\alpha_{\text {int }}\left(u f(x)-\eta_{\text {vol }}(x, \Phi) \beta_{\text {int }} x\right) \\
y & =x \\
z & =\eta_{\text {vol }}(x, \Phi) \beta_{\text {int }} \frac{30}{N_{e}} x
\end{aligned}\right.
$$

Table 2. Variables description

\begin{tabular}{|c|c||c|c|}
\hline Variable & Symbol & Variable & Expression \\
\hline$u$ & $S_{t h}$ & $\alpha_{i n t}$ & $\frac{R T_{\operatorname{man}}}{V_{\text {man }}}$ \\
$x$ & $P_{\text {man }}$ & $\beta_{\text {int }}$ & $\frac{V_{c y l}}{R T_{\text {man }}} \frac{N_{e}}{30}$ \\
$y$ & $P_{\text {man }}$ & & \\
$z$ & $M_{\text {air }}$ & & \\
\hline
\end{tabular}

\section{CONTROL STRATEGY}

Figure 4 details the control strategy we propose. We now present its five constitutive blocks. 


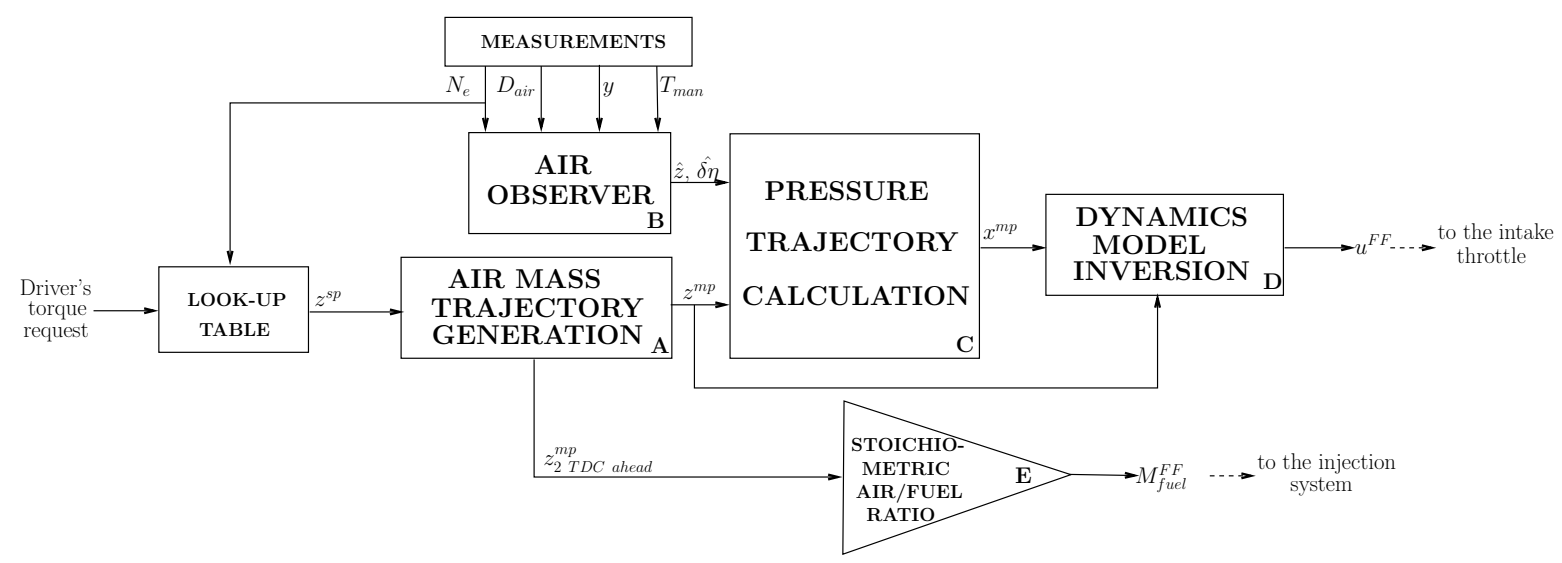

Fig. 4. Feedforward control strategy for the airpath system. The unique closed loop is through the observer. Its estimates are used in the derivation of the open-loop control law $u^{F F}$. Block B uses equation (7), block $\mathrm{C}$ uses equation (10) and block D uses equation (11).

Air mass trajectory generation (block A) The torque demand is directly specified by the driver through the acceleration pedal. This information is converted into a trapped air mass set point, $z^{s p}$, thanks to a two dimensional look-up table (experimentally determined on a test bench) having torque and engine speed as inputs. This information is then filtered to create a feasible trajectory of trapped air mass. We do not detail this filter here. Its structure is discussed in (Chauvin et al., 2006a). We note $z^{m p}$ the obtained air mass trajectory.

Air observer (block B) This block contains an observer that estimates the air mass trapped into the cylinders $\hat{z}$ from engine speed, $N_{e}$, intake flow, $D_{\text {air }}$, intake pressure, $y$, and intake temperature, $T_{\text {man }}$, measurements. It uses a model of the intake manifold and takes VVT variations into account. This is presented in Section 4. This observer also estimates the fluctuation of the volumetric efficiency.

Pressure trajectory calculation (block C) Here, the desired air mass trajectory $z^{m p}$ is turned into a pressure trajectory $x^{m p}$ from the dynamics equation of the intake manifold. This block uses the estimation $\hat{z}$ and the reconstructed volumetric efficiency variation $\hat{\delta \eta}$ coming from block B. In this paper, we do not tackle turbocharged conditions (intake pressure higher than 1 bar) which will be discussed in a next paper. However, we take into account the upstream throttle pressure in simulation, $P_{\text {int }}$, which is varying because of compressor rotation. This block is detailed in Section 5 .

Dynamics model inversion (block D) This block generates an open-loop control law $u^{F F}$ to keep the aspirated air mass equal to the desired air mass, $z^{m p}$. This feedforward term is determined by inverting the intake manifold dynamics. This computation is presented in Section 5 .

Stoichiometric air/fuel ratio (block E) This block computes a fuel mass set point to keep the air/fuel ratio to the stoichiometric value.It is simply determined by applying the following stoichiometric relationship between air and fuel

$$
M_{\text {fuel }}^{F F}=\frac{1}{14.6} z_{2 T D C \text { ahead }}^{m p}
$$

\section{AIR MASS ESTIMATION}

We now detail the design of the air observer (block B). Previously $\eta_{v o l}(x, \Phi)$ was defined as the cylinder filling volumetric efficiency. For sake of simplicity, it is usually assumed that $\eta_{v o l}$ depends only on engine speed and intake pressure. To model the influence of the VVT, we consider a correcting term $\delta \eta$. Then, equation (2) becomes

$$
D_{\text {asp }}=\left(\eta_{\text {vol }}\left(x, N_{e}\right)+\delta \eta\right) \beta_{\text {int }} x
$$

This approach follows several ideas proposed in (Andersson and Eriksson, 2001), (Stotsky and Kolmanovsky, 2002), (Chauvin et al., 2006b). The correcting term $\delta \eta$ is used to estimate the trapped air mass $z$ thanks to the relationship $z=D_{a s p} \frac{30}{N_{e}}$. We propose to estimate $\delta \eta$ with an observer using intake pressure measurement.

Let $x_{1} \triangleq x$ and $x_{2} \triangleq \delta \eta$ be the states of the observer. The measurement is noted $y$. Considering equations (1) and (5), the reference model of the intake manifold writes

$$
\left\{\begin{aligned}
\dot{x}_{1} & =\alpha_{i n t}\left(D_{\text {air }}-\left(\eta_{\text {vol }}\left(x_{1}, N_{e}\right)+x_{2}\right) \beta_{\text {int }} x_{1}\right) \\
\dot{x}_{2} & =0 \\
y & =x_{1}
\end{aligned}\right.
$$

We propose the following observer 


$$
\left\{\begin{aligned}
\dot{\hat{x}}_{1}= & \alpha_{i n t}\left(D_{\text {air }}-\left(\eta_{\text {vol }}\left(y, N_{e}\right)+\hat{x}_{2}\right) \beta_{\text {int }} \hat{x}_{1}\right) \\
& -L_{1}\left(\hat{x}_{1}-y\right) \\
\dot{\hat{x}}_{2}= & L_{2}\left(\hat{x}_{1}-y\right)
\end{aligned}\right.
$$

where $\left(L_{1}, L_{2}\right) \in\left(\mathbb{R}^{+} \backslash\{0\}\right)^{2}$. The state-error is $\tilde{x}=x-\hat{x}$. It satisfies

$$
\left\{\begin{aligned}
\dot{\tilde{x}}_{1}= & \alpha_{\text {int }} \beta_{\text {int }}\left(-\left(\eta_{v o l}\left(y, N_{e}\right)+x_{2}\right) \tilde{x}_{1}-\hat{x}_{1} \tilde{x}_{2}\right) \\
& -L_{1} \tilde{x}_{1} \\
\dot{\tilde{x}}_{2}= & L_{2} \tilde{x}_{1}
\end{aligned}\right.
$$

There, we see the importance of using the air mass flow measurement $D_{\text {air }}$ instead of the throttle flow $u f\left(x_{1}\right)$ in the observer structure. Thanks to this arbitrary choice in the observer design, the $D_{a i r}$ term is cancelled out in the error system (8) and the control variable $u$ does not appear anymore. Observer design and controller design can be treated separately.

Gains are chosen as follows

$$
L_{1}=\alpha_{\text {int }} \beta_{\text {int }} l_{1} \text { and } L_{2}=\alpha_{\text {int }} \beta_{\text {int }} \hat{x}_{1} l_{2}
$$

where $l_{1}$ and $l_{2}$ are positive constants. With this choice, the error system writes

$$
\left\{\begin{aligned}
\dot{\tilde{x}}_{1}= & \alpha_{i n t} \beta_{\text {int }}\left(-\left(\eta_{v o l}\left(y, N_{e}\right)+x_{2}+l_{1}\right) \tilde{x}_{1}\right. \\
& \left.-\hat{x}_{1} \tilde{x}_{2}\right) \\
\dot{\tilde{x}}_{2}= & \alpha_{\text {int }} \beta_{\text {int }} \hat{x}_{1} l_{2} \tilde{x}_{1}
\end{aligned}\right.
$$

Theoretical convergence proof is discussed in (Leroy et al., 2007).

\section{AIR MASS CONTROL}

The air path control strategy we propose consists of managing the trapped air mass in the cylinders. The idea is not to improve the existing control in terms of speed or control effort but to master the air mass trajectory with the intention of improving air/fuel ratio control during torque transients. Trapped air mass depends on intake pressure and other parameters (see discussion in Section 2). In this paper, we do not consider the control of the VVT actuators but we which to counteract their influences on trapped air mass. The only actuator left is thus the throttle.

\subsection{Motion planning}

It is desired to accurately control the trapped air mass in the cylinders. A trajectory is generated from the air mass set point $z^{s p}$. The filter we use is presented in (Chauvin et al., 2006a). This yields an air mass motion planning trajectory $z^{m p}$. Yet, the balance equation (4) is expressed in terms of the intake pressure $x$. So, we need to cast the air mass motion planning trajectory into an intake pressure motion planning trajectory $x^{m p}$. This is not quite simple because the relationship between these two variables is uncertain. Let us write

$$
z=\varphi(x)=\left(\eta_{\text {vol }}\left(x, N_{e}\right)+\hat{\delta \eta}\right) \beta_{\text {int }} \frac{30}{N_{e}} x
$$

where $\hat{\delta \eta}$ is given by the air observer. Equation (9) can be inverted with respect to $x$, yielding

$$
x^{m p}=\varphi^{-1}\left(z^{m p}\right)
$$

For that purpose, a Newton algorithm with constant step can be used.

The generated pressure trajectory highly depends on the air observer results. We will see in Section 6 that transient performance losses may occur if the observer converges too slowly.

\subsection{Dynamics model inversion}

System (4) is invertible. Thus, an analytic expression of the input can be derived from the state variable $x$ and its first derivative history. In fact,

$$
u=\frac{1}{f(x)}\left(\frac{\dot{x}}{\alpha_{i n t}}+\varphi(x) \frac{N_{e}}{30}\right)
$$

In this last expression, $\alpha_{i n t}$ and $N_{e}$ are given by sensor measurements. The unique open-loop control law $u^{F F}$ corresponding to any desired $z^{m p}$ trajectory is

$$
u^{F F}=\frac{1}{f\left(x^{m p}\right)}\left(\frac{\dot{x}^{m p}}{\alpha_{i n t}}+z^{m p} \frac{N_{e}}{30}\right)
$$

where $x^{m p}=\varphi^{-1}\left(z^{m p}\right)$.

\section{SIMULATION RESULTS}

\subsection{Tests setup}

The proposed motion planning control strategy has been tested in simulation. The simulator under consideration is a high frequency engine model developed on AMESim platform (Le Berr et al., 2006).

\subsection{Results}

Figures 5 presents experimental open-loop results. We test the control strategy on a torque trajectory at constant engine speed (1500 rpm). VVT actuators are not plotted in the figure, but they move according to the engine speed and the air mass trapped. We now detail these experiments. 
(a)

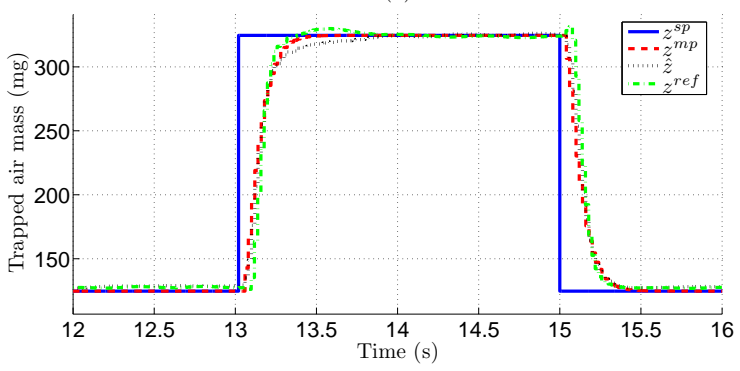

(c)

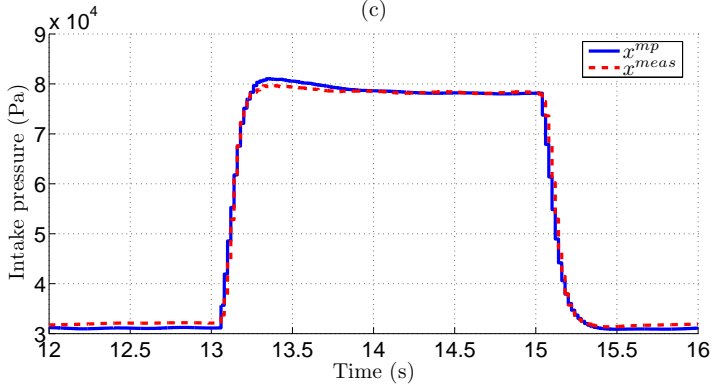

(b)

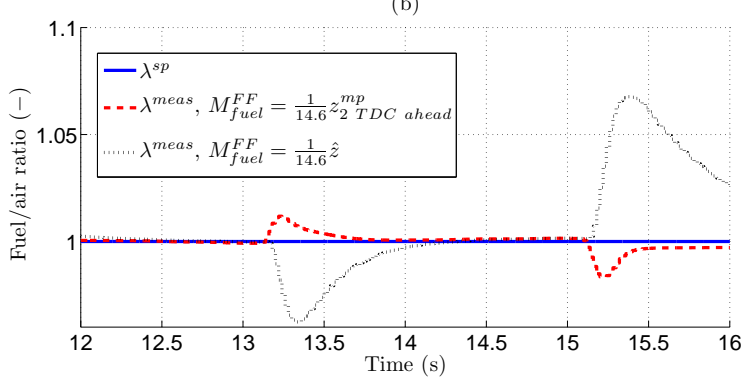

(d)

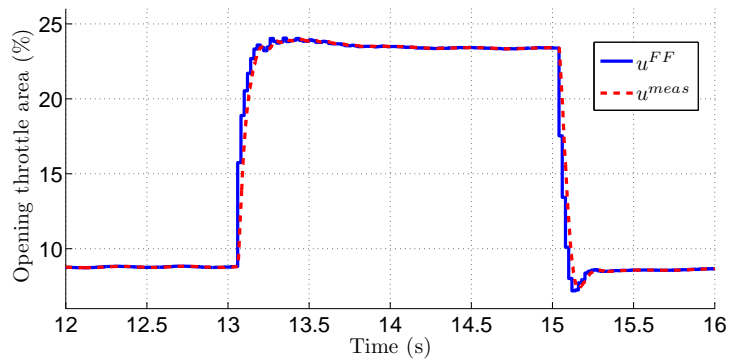

Fig. 5. Simulation results: torque transient from 20 to $100 \mathrm{Nm}$ and then to $20 \mathrm{Nm}$ at $1500 \mathrm{rpm}$. (a) Solid: air mass set point $z^{s p}$. Dashed: generated trajectory $z^{m p}$. Dotted: observed trapped air mass $\hat{z}$, Dashdot: reference AMESim trapped air mass $z^{\text {ref }}$. (b) Solid: stoichiometric fuel/air ratio, Dashed: measured fuel/air ratio when $z^{m p}$ is the feedforward of the fuel injection set point computation, Dotted: measured fuel/air ratio when $\hat{z}$ is the feedforward of the fuel injection set point computation. (c) Solid : Generated pressure trajectory $x^{m p}$, Dashed : Measured intake pressure $x^{\text {meas }}$. (d) Solid: opening throttle area feedforward command $u^{F F}$, Dashed: measured openning throttle area $u^{\text {meas }}$. A first order dynamics is given to the throttle actuator.

1) From $t=12 \mathrm{~s}$ to $t=14 \mathrm{~s}$ : we have here a classic tip-in. Torque starts at $20 \mathrm{Nm}$ and reaches $100 \mathrm{Nm}$. Figure 5 (a) shows the trapped air mass set point $z^{s p}$ and the filtered $z^{m p}$ trajectory. The trajectory generation filter is tuned to be smooth enough to avoid generating a non feasible trajectory, and not too slow, to keep a certain reactivity in torque response. Air estimation $\hat{z}$ given by the observer and AMESim reference trapped air mass $z^{r e f}$ are also plotted in the figure. We can see that convergence of the observer through the reference is pretty slow. This is the real bottleneck of our strategy here. Relatively poor convergence has an impact that can be seen in Figure 5 (c). Actually, an overshoot is created on the $x^{m p}$ trajectory. This can be explained by looking at equation (9), $x^{m p}$ depending on $\hat{\delta \eta}$. We come across this large overshoot in throttle command $u^{F F}$ in Figure 5 (d) and of course on reference air mass trapped in the cylinder $z^{\text {ref }}$ in Figure 5 (a). Figure 5 (b) gives the fuel/air ratio measurements in the case we give the estimated air mass $\hat{z}$ and in the case we give the 2 TDC ahead generated trajectory $x^{m p}$ for the fuel set point computation. There we see the relevance of the presented method looking at the very low excursions of the air/fuel ratio.

2) From $t=14 \mathrm{~s}$ to $t=16 \mathrm{~s}$ : we have now a classic tip-out. Torque starts at $100 \mathrm{Nm}$ and decreases to
$20 \mathrm{Nm}$. Observation errors are almost the same as for tip-in transient except that the reference trapped air mass $z^{\text {ref }}$ is much better. Actually, after the transient, $u^{F F}$ solely depends on $z^{m p}$ and $f\left(x^{m p}\right)$. Now considering chocked flow conditions (see equation (3)), $u^{F F}$ does not more depends on $x^{m p}$. The overshoot is therefore avoided.

\section{CONCLUSION}

This paper presents a motion-planning based method of controlling the air path of a downsized SI engine equipped with VVT actuators.

Simulation results stress the efficiency of the approach. However, the relative slowness of the air observer generates over and undershoots on reference trapped air mass during torque transients. Improving convergence of the observer seems a natural direction for further investigations. When this problem is resolved, we plan to add a feedback term to the throttle control to cancel further modelling errors. Another PI controller could also be considered for the fuelpath control.

\section{REFERENCES}

Andersson, P. (2005). Air Charge Estimation in Turbocharged Spark Ignition Engines. PhD thesis. Linköpings Universitet. 
Andersson, P. and L. Eriksson (2001). Air-tocylinder observer on a turbocharged SI-engine with wastegate. In: Proc. of SAE Conference. number 2001-01-0262.

Chauvin, J., G. Corde, N. Petit and P. Rouchon (2006a). Experimental motion planning in airpath control for HCCI engine. In: Proc. of the American Control Conference.

Chauvin, J., N. Petit, P. Rouchon, G. Corde and C. Vigild (2006b). Air path estimation on Diesel HCCI engine. In: Proc. of SAE Conference. number 2006-01-1085.

Chevalier, A., C. Vigild and E. Hendricks (2000a). Predicting the port air mass flow of SI engines in air/fuel ratio control applications. In: Proc. of SAE Conference. number 2000-01-0260.

Chevalier, A., M. Müller and E. Hendricks $(2000 b)$. On the validity of mean value engine models during transient operation. In: Proc. of SAE Conference. number 2000-01-1261.

Eriksson, L., L. Nielsen, J. Brugard, J. Bergström, F. Pettersson and P. Andersson (2002). Modeling of a turbocharged SI engine. In: Proc. of Control Engineering Practice. Vol. 26. pp. 129-137.

Grizzle, J.W., J.A. Cook and W.P. Milam (1994). Improved cylinder air charge estimation for transient air fuel ratio control. In: Proc. of the American Control Conference.

Guzzella, L. and C.H. Onder (2004). Introduction to Modeling and Control of Internal Combustion Engine Systems. Springer.

Heywood, J. (1988). Internal Combustion Engine Fundamentals. McGraw-Hill, Inc.

Le Berr, F., M. Miche, G. Le Solliec, F-A. Lafossas and G. Colin (2006). Modelling of a turbocharged SI engine with variable camshaft timing for engine control purposes. In: Proc. of SAE Conference. number 2006-01-3264.

Lecointe, B. and G. Monnier (2003). Downsizing a gasoline engine using turbocharging with direct injection. In: Proc. of SAE Conference. number 2003-01-0542.

Leroy, T., J. Chauvin, G. Le Solliec and G. Corde (2007). Air path estimation for a turbocharged SI engine with variable valve timing. In: Proc. of the American Control Conference.

Stotsky, A. and I. Kolmanovsky (2002). Application of input estimation techniques to charge estimation and control in automotive engines. In: Proc. of Control Engineering Practice. Vol. 10. pp. 1371-1383. 